\title{
Innovative Project Idea Maturation: An Important Part of Governance
}

\author{
Jan Pries-Heje and Ann-Dorte Fladkjær Nielsen \\ Roskilde University, Universitetsvej 1, DK-4000 Roskilde \& \\ Jyske Bank, Vestergade 8-16, DK-8600 Silkeborg \\ Tel.: +452347 4463, +4589892765 \\ janph@ruc.dk, afn@jyskebank.dk
}

\begin{abstract}
Project Governance includes the elicitation of ideas for projects, choosing the best ideas, initiating projects, assigning resources, and nurturing the projects to success. In the third largest bank in Denmark - Jyske Bank - IT project managers often became uncertain when they were assigned new projects; their descriptions were either to vague or broad or sometimes even both. There was a need for better project scoping and improved idea descriptions. In this paper we describe how we committed ourselves to solve this problem. Based on a literature study on innovation and using an existing creative space (room) called the "land of opportunity", we used a design science approach to formulate a new idea maturation concept. Here two years later, we have developed and evaluated our concept on several project ideas. The uncertain project managers are now very enthusiastic; they really feel that they have a much clearer scope and idea description as well as an early prototype of the idea. After four design iterations, the concept stabilized. In this paper we present the idea maturation concept and the organizational design science research process we have used.
\end{abstract}

Keywords: Governance, project idea, design science research, project management.

\section{Introduction}

Peter Weill \& Jeanne Ross (2004) talk about five key IT decisions in IT governance: (1) IT principles decisions, (2) IT architecture decisions, (3) IT infrastructure decisions, (4) Business application needs, and (5) IT investment and prioritization decisions. As part of the last decision area project governance is a major part. Project Governance includes the elicitation of ideas for projects, choosing the best ideas, initiating projects, assigning resources, and nurturing the projects to success. Only then can the investment represented by the projects be 'harvested'.

Jyske Bank is Denmark's third largest bank, formed through a merger of smaller banks in 1967 and headquartered in Silkeborg. There is still a long way to the two largest banks in Denmark, so Jyske Bank is very conscious of differentiating themselves. "Make a Difference" is their mantra. On their homepage Jyske Bank presents themselves as the (social) climber in the banking industry who "always treads new 
paths." Innovation has, for many years, been an important parameter to differentiate Jyske Bank from others. In order to differentiate oneself and be innovative, one must constantly come up with new ideas. In Jyske Bank, the effort towards this has been very conscious. Among others, they have designed a large room on the ground floor in the Silkeborg headquarters, dubbed "the land of opportunity." The room is furnished as a fantasy world based on Norse mythology, with a large painting in one end of the room and a wide canvas in the other. Colours, soft shapes and flexible partitioning is part of the design. Even the coffee mugs and the cutlery are "different". The room's purpose is to promote the creative process, by bringing humans into other environments than those they are usually surrounded by in their work.

Many good ideas arise around Jyske Bank, but they are not always presented or described well enough. In autumn 2007 an interview survey among project leaders revealed that the individuals often felt that the project descriptions they were given were too vague and superficially described, so they felt uncertain about the projects they were responsible for. The survey led to the creation of a new project, with the definition that Jyske Bank did not need more ideas, but better descriptions of the ideas. Focus was thus the transformation from draft proposals to better project descriptions. We formulated the central question as thus: What does a concept for better project descriptions look like?

\section{How is the remainder of the paper organized?}

The remainder of the paper is structured as follows. First, we talk about the theoretical anchorage of the concept, both in innovation theory, and in situational theory. Then we briefly describe our approach as a mixture of action research and design science. Thereafter follows a long section where we describe the concept in detail. This is followed by a series of selected examples of the use of the concept. Finally, we summarize the points of the article and discuss further research.

\section{Creativity and Innovation}

"Creative" comes from the Latin Creare, which means to create. As a starting point, "Creative" is a positive word, (something everybody looks positively on). A usable definition of creativity is: "A systematic to break the habit of thinking". Innovation is the deployment of an idea or an approach that relates to a product, service, device, system, policy or program that is new to the organization deploying it (Damanpour \& Gopalakrishnan, 2001). Coming up with new ideas is creative. To implement it is innovation - when it is experienced as new and creates something of value.

Edward de Bono (1968, 1969, and 1970) did research on how people think, be it innovative and/or creative. De Bono notes that all self-organizing systems form patterns - habits, we call it often. This means that one is forced to move across these patterns instead of just following them, if one wants to think thoughts that are different. De Bono calls this "Lateral Thinking".

If one is to think laterally - to the side - then it is necessary to put oneself in a situation that changes ones starting point and perception of how things link, to actually force one to think in a fundamentally different way. 
Another source of inspiration is IDEO (Kelley \& Littman 2001, Kelley 2005) that helps companies innovate. They create strategies for innovation and they design products, spaces, services and experiences. Key to their success as a design and innovation firm are the insights they derive from understanding people and their experiences, behaviours, perceptions and needs.

Donaldson (2001, p.5) defines contingency theory in the following way: "At the most abstract level, the contingency approach says that the effect of one variable on another depends on some third variable ..." The core of the situational theory, therefore, is that organizations that want to work optimally need to take account of the situation; it is the factors of the situation that determine what the best approach would be. Contingent models have, for example, been applied in vague and ambiguous situations, where the information available could be interpreted in many ways depending on perspective (Galegher \& Kraut, 1994). Contingency factors have included leadership style (Hersey \& Blanchard, 1969, 1981), communication support, process structuring and information processing (Zigurs \& Buckland, 1998; Zigurs, Buckland, Connolly, \& Wilson, 1999), as well as task complexity and whether the technology is appropriate for the task (Van de Ven \& Drazin, 1985).

Contingency theory has been criticized for having an excessively static view of the relationship between structure and technology (Barley, 1990). Nevertheless, we found characteristic features in the situation, related to the idea maturation context, that we then used to develop a situation specific concept. Obviously we can not rule out that it is a very static picture we've seen, that would be are outstripped by the dynamics of reality; but it has simply not occurred here more than a year after we identified the main situation specific factors.

\section{Research Method}

Herbert A. Simon (1996) defined in the book "The Sciences of the Artificial", a science that focuses on design/construction of artefacts or human systems with the "desired" properties. Simon defined design science as the counterpart to the (natural) sciences that study given things (in nature or society) and how they work.

Hevner et al. (2004) presents a definition of Design Science Research (DSR) and outline three key processes. First there is iteration between building and evaluation. Second is the relevance-process, i.e. once the design has gone through a number of iterations in the middle, it turns back and is attempted to be used to meet the needs or solve the problem. Third, we find the research process ("rigor"), where the input from the existing research knowledge base is obtained, and it is reported what contributions to scientific knowledge the design allows. Whether the knowledge is in the form of theory, model, method, framework or something similar, it is the researchers job to take existing knowledge into account, and "stand on the shoulders of it" i.e. to build on the existing. Thus DSR relates to the needs and problems with focus on satisfying the needs or solving the problems. Design science is prescriptive, or perhaps even normative. Thereby, design science differs from analytically oriented sciences, where the objective is to understand and describe.

We decided to use DSR as our approach for designing and building a solution to the problem at hand in Jyske Bank, for testing it, learning from it and becoming wiser, 
built an improved concept, test it, learn from it and become wiser, etc. The main reasons for choosing DSR was the close engagement with practice, the iterative nature of DSR that ensures that learning can be captured and used. Further the 'scientific' cycle of DSR ensures that what is designed is done on a sound scientific state-of-the-art foundation.

The first version of the idea maturation concept was developed after studying the problem and its scope closely (relevance process). We interviewed around 10 projectmanagers in the organization and dived into the old project descriptions and business cases to get insight into the content and quality of it. It quickly became clear that many immature ideas were launched. This was documented in a presentation that spawned our work on creating a concept that could improve project descriptions.

It was with these inputs, as well as our own experience and the knowledge that the literature on innovation and creativity has given us (the research process) that the first version of the concept saw the light of day.

Alongside studying projects from their own organization, we read what others had written about for example innovation. The literature gave us an overview and inspired us to create a concept that could actually be used to improve and mature ideas.

We worked with the concept in four design iterations. Our first version of the concept was ready in June 2008. In each iteration, we have received feedback from users, and their comments for each step in the process gave rise to (many) adjustments.

In general we have chosen a naturalistic examination (Venable, 2006) in a real organization - Jyske Bank - with a perceived problem. The first evaluation trial took place in June 2008. This evaluation gave rise to many changes in the first version of the concept. The same happened after the second and third evaluation of the concept.

\section{The Idea Maturation Concept}

Finally in 2009 we ended up with the concept presented here with four steps:

- Step 1: A discussion of: How clear is your idea?

- Step 2: Determining what idea maturation process would be best suited for that specific business idea?

- Step 3: Arrange idea maturation workshop

- Step 4: Secure results of idea maturation process including relevant reviews

The purpose of step 1 - How clear is your idea? - is to uncover a focused phrase that describes the idea. Experience from Jyske Bank shows that it is often wasted work to pursue an idea if the wording is unclear. That is similar to having been through a phase with divergent thinking, but without closing and deciding, similar to the convergence phase (Jakobsen \& Rebsdorf, 2003).

To be sure that the idea owner has the right starting point for further idea maturation, we have selected some questions from (inspired by Pries-Heje et al., 1999), which gives a clear indication of whether the idea is sharp (= clear wording of idea convergent phase completed) or open (= unclear wording of idea - convergent phase not completed). 
The questions we use in the concept to be answered by the idea owner is shown in Figure 1. It takes approximately an hour to give and receive answers to the questions in Figure 1. We note the idea owner's responses as they are obtained. There are 3 possible outcomes of Step 1:

1. The idea owner has a concrete answer to the questions (Figure 2) and is therefore ready for step 2 of the concept.

2. The idea owner has been unable to respond to one or more of the questions and should therefore continue working to concretize the idea before it the idea is pursued. (New meeting is planned)

3. Idea owner has found out that the idea is not sustainable enough and the work on the idea ends here.

The knowledge that is the result of questions and answers session can be used directly in various sections of the project description. As a result, the idea owner is no longer left standing with just a blank and empty description.

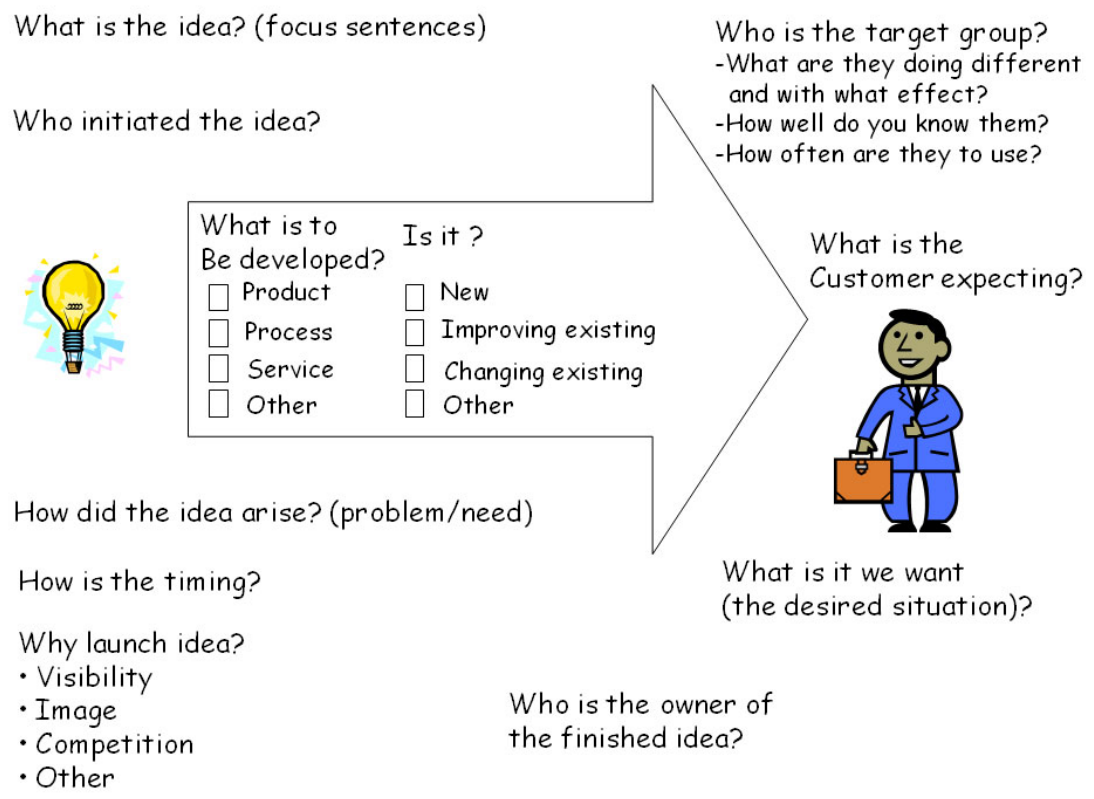

Fig. 1. Artefact from workshop used to give an overview of the questions in step 1 of the idea maturation concept

The purpose of Step 2 is to get a characterization of the idea, so that we can find the idea-process just sufficient enough to mature the idea. The idea-owner will be asked to decide which group of statements from Figure 2 best matches his idea. 


\begin{tabular}{|c|c|}
\hline $\begin{array}{l}\text { TYPE } 1 \\
\text { - The idea may be vital for Jyske Bank } \\
\text { - The idea may be a new business or } 1 / \text { more } \\
\text { business areas seen in a whole new light } \\
\text { - The idea may be difficult to predict } \\
\text { - The idea has not yet become a common } \\
\text { awareness among all key stakeholders } \\
\text { - We will read about it in the newspaper when } \\
\text { this idea is realized } \\
\text { - The idea may intervene with Jyske Bank's } \\
\text { strategy }\end{array}$ & $\begin{array}{l}\text { TYPE } 3 \\
\text { - The idea can be compared to anything we } \\
\text { know (everyday situations) } \\
\text { - The idea stems from an easily } \\
\text { understandable, everyday need (something an } \\
\text { advisor / client is missing in their everyday } \\
\text { life) } \\
\text { - Realization of the idea requires no new } \\
\text { knowledge at Jyske Bank } \\
\text { - The idea is already fully or partially on the } \\
\text { market but not at Jyske Bank }\end{array}$ \\
\hline $\begin{array}{l}\text { TYPE } 2 \\
\text { - The idea requires that many different } \\
\text { experts give their input before the project } \\
\text { configuration can be written } \\
\text { - The idea should be studied from many } \\
\text { viewpoints } \\
\text { - The idea has many interfaces } \\
\text { - The idea will lead to more } 50 \% \text { renewal as } \\
\text { seen from the target audience's point of view } \\
\text { - The idea is an expression of something need } \\
\text { to have compared to Jyske Bank's overall } \\
\text { strategy }\end{array}$ & $\begin{array}{l}\text { TYPE } 4 \\
\text { - The idea is based on something already } \\
\text { known at Jyske Bank, but must be extended, } \\
\text { renewed or corrected } \\
\text { - The idea must be resolved by Jyske Bank's } \\
\text { own specialists } \\
\text { - The idea must fit into the existing set up } \\
\text { - The idea is an expression of something need } \\
\text { to have viewed from the target audience's } \\
\text { point of view } \\
\text { - The idea did not change significantly in the } \\
\text { target group's way of thinking and acting }\end{array}$ \\
\hline
\end{tabular}

Fig. 2. The four innovation types included in step 2 of the idea maturation concept

The type with the largest amount of fitting statements is the type that forms the basis for further work on the idea. Each grouping has a corresponding idea maturation process, a number of techniques, proposition of participants, etc. The four types represent the contingency factors that we found central in idea maturation at Jyske Bank. Radical innovation connotes groundbreaking innovation: the surprisingly new, that in a radically new concept links technology and value from use. Incremental innovation connotes innovation in small steps where existing concepts are linked in a new way. Often, it is a question of continuous improvements and adaptation of existing products. We could have done far more than four types, but to ensure its practical applicability we ended up restricting ourselves to four main groups. Together, the four types cover the entire innovative spectrum, from radical to incremental innovation (Dewar \& Dutton, 1986)

\section{The Four Innovation Types in the Idea Maturation Concept}

In Figure 3 we have shown the four innovation processes that are implicit in the four innovation types covered by our concept. The result of a workshop is always a prototype that visually describes the ideal solution or solution elements.

Radical innovation often has a very divergent and convergent phase. In Figure 3, the divergent part is illustrated as a lateral "V", which opens from left to right. Similarly, the convergent part is illustrated as an interim "V", which closes from left to right. The difficulty of an idea maturation workshop for radical innovation is that the 
uncertainty is very high. Some workshop participants won't be comfortable with very high uncertainty. It may also be that the participants at the workshop are okay with it, but it is as much about the organization's expectations: "Will we get some answers to our questions soon?" rather than just generate more questions. Therefore, it has to be a very 'strong' idea-owner to be responsible for an idea of this nature. Otherwise, you risk the process being closed too rapidly - it travels too fast from divergent to convergent - and then the result won't be radical innovation anyhow.
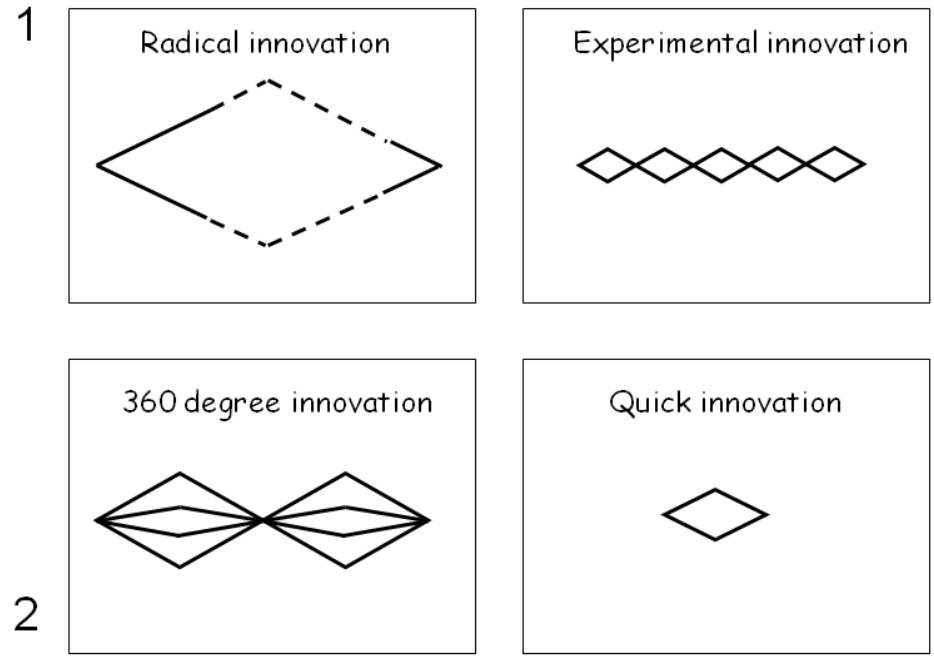

4

Fig. 3. How the process runs dependent on innovation type

360 degrees innovation, corresponding to drawing 2 in Figure 3, is special because each of the divergent and convergent phases needs to be able to handle several different opinions and angles. There might, for example be several target groups that have to be evaluated at the same time. Or it could be several sources of inspiration that are used in parallel. Idea maturation workshops of this nature are often more complex, and require more advanced techniques and external contributions. We spend from 1-2 days on workshops of this type.

Experimental innovation, equivalent to drawing 3 in Figure 3, has a lot of small and rapid divergent and convergent phases. This workshop is about developing some ideas and getting them translated into a prototype that can be assessed and improved. The improvements should in turn be incorporated in the prototype and evaluated, etc. This process is repeated until the user accepts the prototype. Often we use 1 day on the idea maturation workshop.

Quick innovation (drawing 4 in Figure 3) is a single small process, where we get through both a divergent and a convergent phase in a very short time span. We use simple techniques that are known to many in the organization. An idea maturation workshop of this type often takes 2-4 hours. To get the participants in a workshop to 
identify with the activities related to the situation-specific group, we decided to use metaphors. Something similar has been done with very good results in systems development (Kendall \& Kendall, 1993 \& 1994).

More specifically, in the workshop we have chosen to use a travel metaphor corresponding to the four types as follows:

\section{Type 1 is 'The journey into space'}

This means that we are going to face the completely unknown. It is essential to think in a totally new way. We need to create something that no one has seen before

\section{Type 2 is a trip 'Around the world'}

This means that we need to examine varied sources of inspiration, look elsewhere, try to work in a different way, etc., to conceive completely new ideas into the existing situation. We know what the job is, but can it be done in another way?

\section{Type 3 is a 'fieldtrip to a science lab in Silicon Valley'}

This means that we must experiment our way to a solution. We need to work with prototypes, assessments, improvements. We steal with arms and legs! We need not reinvent the wheel again.

\section{Type 4 is a 'Shopping trip to London'}

This means that what we are looking for are easy, small and fast methods to get a lot of ideas out in the open and then select the best - one or more. We're short on time, but we would like to spend some of it getting the good ideas out. Maybe a slightly more modern product will cover more needs. Often adds bits to something existing.

Travel metaphors have proven to work really well at giving participants a sense of how much innovation is required for idea maturation. Moreover, the travel metaphor gives inspiration to the staging of the workshop. We aim to adjust the staging to fit the idea. If we are to mature an idea that falls into group 4: 'Shopping trip to London' we aim to create a workshop environment with shops, for the right age group and market segment.

As part of the concept, step 2, we co-operate with the idea-owner to asses who should participate in the workshop. The purpose of step 3 - arranging the idea maturation workshop - is to get a group of well-chosen people to specify the idea and generate proposals for the first draft of the solution. The result of step 3 is a clear description of which solution proposals or solution elements to pass on to a development project - including a clear definition of what to include and what to exclude. Also step 3 results in a simple prototype that visualizes the product or process being generated by the idea.

Many different creativity increasing techniques can be found in the literature. We have tested many but have no final set of techniques to recommend. We can only say that it is contingent on the experience of the participants and the facilitator. We use the travel metaphor to plan the progression of the workshop. First we're going out and 
then were returning home - we must first open, then close the idea generating process - divergence and convergence.

The prototype developed at the workshop need not be a working functional prototype. It may be a simple drawing of a process, a sketch of a product or something similar. For the workshop we use "the land of opportunity". Figure 4 shows an example of the workshop setup from "a hike in the Alps"; the idea is to imagine being in a tent camp in the mountains.

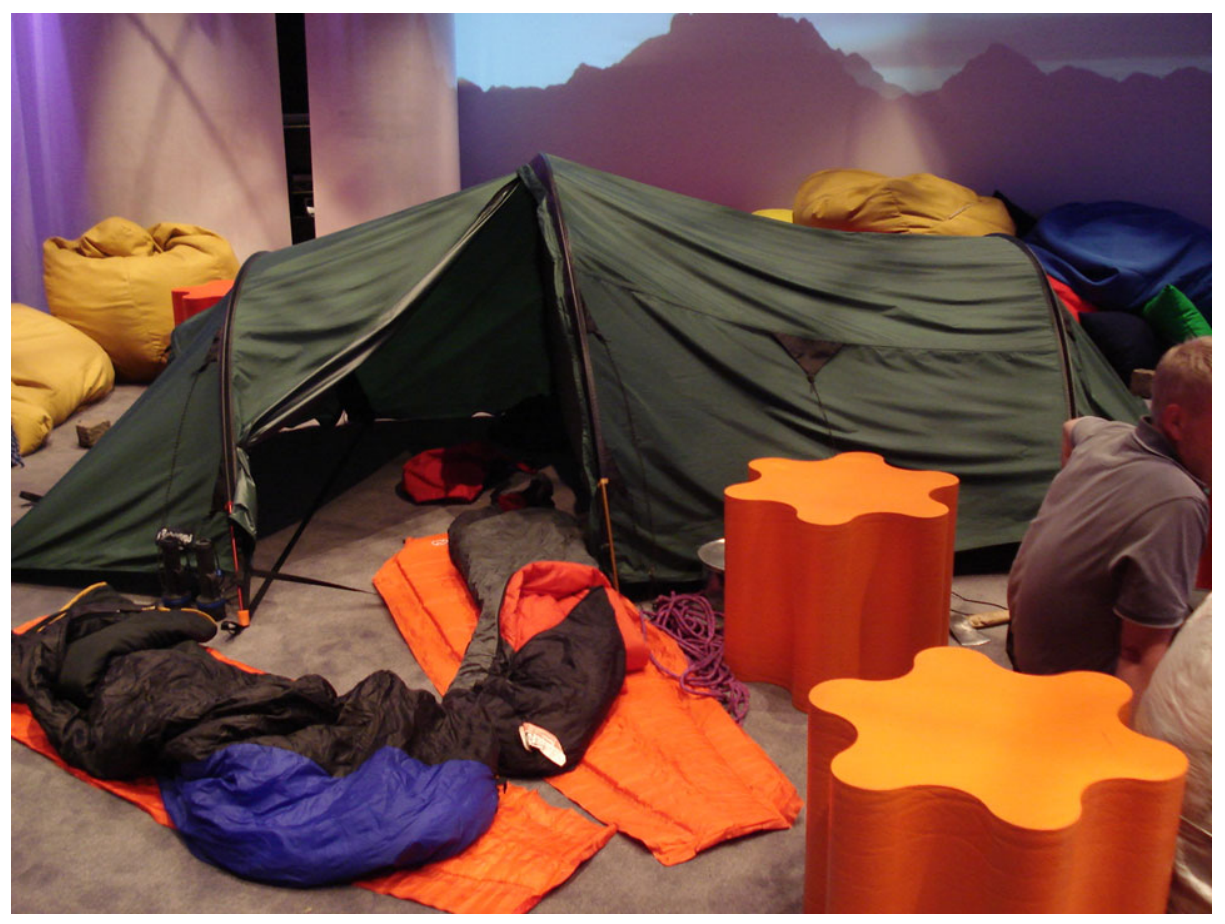

Fig. 4. Tent camp in the Alps; a travel metaphor implemented in the "land of opportunity"

We have also found that things like appropriate catering, music and effects that the participants can touch and play with are important and help them live themselves into the fantasy.

At the beginning of a workshop we have found it to be a good idea to have an employee from the business area of the idea tells a little about how the new idea fits into the overall strategy of the company, the thoughts behind the idea, if the idea is part of a larger context etc. We have also had inspirational presentations from external specialists. If the purpose is, for example, to come up with ideas for the customer segment from 18 to 24 years, it might be appropriate to have a futurologist talk about current or upcoming trends for this segment. 
Table 1. Four examples of projects and innovation types

\begin{tabular}{|c|c|c|}
\hline No. & Project \& Type & Result \\
\hline 1 & $\begin{array}{l}\text { Strategic concept for } \\
\text { corporate customers \& } \\
\text { 360 degree } \\
\text { innovation }\end{array}$ & $\begin{array}{l}\text { A strategic concept for corporate } \\
\text { customers. Many bank products require } \\
\text { that corporate customers can produce a } \\
\text { strategic plan. However, many small and } \\
\text { medium corporate customers do not have } \\
\text { the ability to develop a proper strategic } \\
\text { plan. Therefore Jyske Bank will offer to } \\
\text { help with it expertise; a kind of add-on } \\
\text { banking product offered to clients. }\end{array}$ \\
\hline 2 & $\begin{array}{l}\text { iVenture \& Radical } \\
\text { innovation }\end{array}$ & $\begin{array}{l}\text { Financial guide to a Jyske Bank advisor } \\
\text { when he is in dialogue with customers. For } \\
\text { risk assessment of clients' securities } \\
\text { composition. }\end{array}$ \\
\hline 3 & $\begin{array}{l}\text { Budget zone in online } \\
\text { banking \& Quick } \\
\text { innovation }\end{array}$ & $\begin{array}{l}\text { New feature included in online banking as } \\
\text { an application for private customers. }\end{array}$ \\
\hline 4 & $\begin{array}{l}\text { Secure buy\& } \\
\text { Experimental } \\
\text { innovation }\end{array}$ & $\begin{array}{l}\text { A new banking product for securing } \\
\text { corporate clients, when trading with } \\
\text { foreign countries. }\end{array}$ \\
\hline
\end{tabular}

In Table 1 we have given four examples of using our idea maturation concept for four different types of innovation.

\section{An Example of an Idea Maturation Workshop}

To convey the core of how the idea maturation workshop is held, we give an example from one of our evaluation. In the example (no. 1 in Table 1) the problem to address was the fact that many SMEs are required to present a strategic plan to Jyske Bank to obtain a loan or another Baking product. However, this requirement can sometimes be difficult to meet for SMEs because they do not have the expertise in-house to develop a strategic plan. Thus the idea we started out from was that the bank could offer customers expertise to help them with their strategy process. This would create a win-win situation in that the companies would get assistance and the Bank would get insight into the company and thereby be able to offer customers the right banking products.

Our focus in this example is on process rather than outcome (the product that was matured). In this example, we will discuss an idea from group 2, so we needed to build an idea workshop with 360-degrees innovation - a trip around the world.

The day began at a check-in counter at the airport. Participants were each provided with a travel suitcase, a boarding pass, a bread roll in a paper bag and a newspaper. Then they were allowed to check in and go ahead with the workshop. This start-up 
was created so the participants could become aware that there would be something different going on - not the usual meeting, nor a normal meeting room.

In the room where the participants entered, we created four different "client countries", in the form of staging of 4 different types of businesses which participants would go to. For each country, participants were given the task to discover what the customer's thoughts about the product/service were. In the carpentry workshop, they literally sat amongst wooden boards, laths and machinery, and tried to imagine how a carpenter thought and felt about the particular subject.

The next process of the workshop was a presentation by an outside consultant. From what he told me and from the inputs the participants had gotten from their travels to different types of businesses, we produced the first draft of a prototype. A process, where the facilitator tried to assemble the many inputs into a drawing, they could all say yes to.

Thereafter, the first prototype had to be made marketable, so the next task was called "How do the advisers work with this model, so the customers experience Jyske Differences?" To get participants to think "differently", we chose to let them work in different cities. We made a scene setup with three different cities (Paris, London and New York). For this, we used images, sounds and props that characterized each of the big cities. Participants would then in turn go to the three cities and gather inspiration on how to market the product. With the combined associations they had created on their journeys, we developed the next version of a prototype. This prototype was then tested against the different types of customers; again in the form of a journey to the four "customer countries".

The above is an example where we constantly "force" the participants to see the problem from different angles. We tried to bring them into realistic environments and environments which could hopefully create very different connotations than the usual ones. We believe that both parts were successful. Also, it should be emphasized that this is only one example. For other idea workshops, we will probably create quite different destinations, tailored to the specific idea. As the example shows, the organization of the idea workshop is contingent on the chosen innovation type. The trip is never a "standard trip".

The outcome related to the idea that has come from steps 1, 2 and 3 needs to be secured and described in a project description. There are several target groups for the project description, which is extremely important to keep in mind when the writing process starts. The target groups are decision makers in the organizations and the upcoming projects and project teams. These two groups have widely varying needs. The decision makers require a project description that describes the project idea in a clear and concise manner with just enough information to enable them to make the decision of whether the project idea is to be realized or rejected.

It is in the interest of the future project -manager and group to have the project presented in such a way, that they are not forced to start from scratch, but can draw on the information that has already been studied and described in the project description.

When the project description has been written - with all the details of steps 1,2 and 3 - it is ready to be enriched. The idea-owner can have two needs of enrichment they may need, some people who can contribute knowledge directly to the project description, or they may need to have internal experts review the resolution, to make sure it is sound and in accordance to Jyske Bank's values and strategies. 


\section{Conclusion and Learning Points}

We believe we have designed a successful idea maturation concept in four steps, which Jyske Bank has benefited considerably from. The largest benefit is when starting a project, as the project group gain a quicker start because the idea is better described and documented through an idea prototype. This means that the project group doesn't waste time getting acquainted with the task, but instead can 'dive' directly into its solution.

The process we designed ensures that you focus better and think the right thoughts before writing the project description. The contribution is the contingent grouping of business ideas, and the consistent use of the groups, as well as metaphors, to determine the actual idea maturation process.

One criticism that we have encountered is that all ideas "swell" with the use of the described concept. To counter this, we can only say that in practical use, the concept has proven not only to get ideas to "swell" up; it has also put ideas to death!

The main adjustments in the four design iterations are summarized in the following ten detailed learning points, structured by the four stages of the concept:

1. Questions should be good enough, to determine whether the idea is viable. The first time around, our questions (see Fig. 2) weren't broad enough and lacked focus on how the idea fit with the bank's overall strategy, the target group's expectations, etc.

2. Reduce contingent groups as much as possible to ensure clarity. We started with 6 contingency groupings with a corresponding travel metaphor, but it soon became apparent that it was too difficult to ask questions that accurately characterized the group; they overlapped to easily.

3. Metaphors may be a hindrance. We found that Innovation Types were easier to understand than the travel / journey metaphor. Innovation types proved to be more understandable for the idea owner. But the journey metaphor is still important to use, to bring about a framework and thereby the staging of the idea maturation workshop.

4. Design presentation style needs adaptation to targets group. We evaluated the production of the idea characteristics in three different ways. They were: (1) XY-axes with statements for given situation factors. (2) Groupings of statements to cross off. (3) A matrix of key statements, which together made a room. As described earlier participants preferred (2), so this is the approach we have presented here.

5. Transformation processes are hard! Generally participating in a creative process such as our idea maturation workshop requires something completely new for the vast majority of our employees. You have to overcome some resistance.

6. It is very important to have the right people must participate in the workshop. In the beginning, we were not focused enough on getting the right people invited to the workshops. After the first two pilot tests we realized the importance; and it made a (positive) difference to have them joining.

7. Very difficult to escape the everyday life and challenges. We have learned that our participants have difficulty getting away from their daily life in the organization. In the first pilot we were not sufficiently aware that the choice of travel metaphor had to be placed in the participants' consciousness several times during the workshop. 
8. People are different. Some are better than others at associating, brainstorming and living themselves into a (travel / journey) metaphor. The concept needs to allow for this difference.

9. Some people are very solution-oriented. Some participants find it very hard to work for period of time in the open phase. They immediately start evaluating ideas and discard some ideas as unrealistic. Thus you need facilitation to "keep" people in the creative mode. In the concrete we have meet four distinct types of people:

1. Those who just throw themselves into deep water and play along

2. Those who can participate well in the creative thinking games, but have a strong need for a facilitator to manage the process

3. Those who might feel as group two, but let's it depend on the rest of their group

4. Those who think stuff like "creative processes" is a complete waste of time

Groups 2 and 3 have in this case been by far the largest groups and roughly equal in size.

10. Continuous adjustment of the project description template has been needed. Thus we have not only designed a new process for idea maturation but also the artefact coming out of idea maturation.

Finally, we have written this paper in the hope that others can use or be guided by our concept. We have emphasised details to an extent where it should be possible to learn from our example. Further, we have given the details of our design science research method thereby giving the academic reader a better insight into our work and giving the opportunity of judging the quality.

\section{References}

Barley, S.R.: The Alignment of Technology and Structure Through Roles and Networks. Administrative Science Quarterly 35(1), 61-103 (1990)

Damanpour, F., Gopalakrishnan, S.: The dynamics of the adoption of product and process innovations in organizations. Journal of Management Studies 38, 45-65 (2001)

De Bono, E.: New think; the use of lateral thinking in the generation of new ideas. Basic Books, New York (1968)

De Bono, E.: The mechanism of mind. Simon \& Schuster, New York (1969)

De Bono, E.: Lateral thinking - creativity step by step. Harper \& Row, New York (1970)

Dewar, R.D., Dutton, J.E.: The adoption of radical and incremental innovations: an empirical analysis. Management Science 32(11), 1422-1433 (1986)

Donaldson, L.: The Contingency Theory of Organizations. Sage Publications, Thousand Oaks (2001)

Galegher, J., Kraut, R.E.: Computer-mediated communication for intellectual teamwork: An experiment in group writing. Information Systems Research 5(2), 110 (1994)

Hersey, P., Blanchard, K.H.: Life Cycle Theory Of Leadership. Training and Development Journal 23(5), 26-34 (1969)

Hersey, P., Blanchard, K.H.: So You Want to Know Your Leadership Style? Training and Development Journal 35(6), 34-54 (1981)

Hevner, A.R., March, S.T., Park, J., Ram, S.: Design Science In Information Systems Research. MIS Quarterly 28(1), 75-105 (2004) 
Jakobsen, H.S., Rebsdorff, S.O.: Idéudvikling ved kreativ innovation. Gyldendal, Copenhagen (2003)

Kelley, T., Littman, J.: The Art of Innovation: Lessons in Creativity from IDEO, America's Leading Design Firm. Broadway Business (2001)

Kelley, T.: The ten faces of innovation. Currency/Doubleday, Random House (2005) ISBN 0385-51207-4

Kendall, J.E., Kendall, K.E.: Metaphors and Methodologies: Living beyond the Systems Machine. MIS Quarterly 17(2), 149-171 (1993)

Kendall, J.E., Kendall, K.E.: Metaphors and their meaning for information systems development. European Journal of Information Systems 3(1), 37 (1994)

Pries-Heje, J., Tryde, S., Nielsen, A.-D.F.: Lær at implementere: Software procesforbedring der virker i praksis. Økonomistyring \& Informatik 15(1) (1999)

Simon, H.A.: The Science of the Artificial, 3rd edn. MIT Press, Cambridge (1996)

Susman, G.I., Evered, R.D.: An Assessment of the Scientific Merits of Action Research. Administrative Science Quarterly 23(4), 582-603 (1978)

Weill, P., Ross, J.: IT Governance: How Top Performers Manage IT Decision Rights for Superior Results, 1st edn. Harvard Business Press, Boston (2004)

Van de Ven, A.H., Drazin, R.: The Concept of Fit in Contingency Theory. Research in Organizational Behaviour 7, 333-365 (1985)

Venable, J.: A Framework for Design Science Research Activities. In: Proceedings of the 2006 Information Resource Management Association Conference, Washington, DC, USA, pp. 184-187 (2006)

Zigurs, I., Buckland, B.: A Theory of Task/Technology Fit and Group Support System Effectiveness. MIS Quarterly 22(3), 313-334 (1998)

Zigurs, I., Buckland, B., Connolly, J.R., Wilson, E.V.: A test of Task/Technology Fit Theory for Group Support Systems. Database 30(3/4), 34-50 (1999) 